\title{
Sorotan Literatur Perbandingan Gagasan Sastera Islami Sayyid Sayyid Abd al-Raziq dan Mohd Affandi Hassan
}

\author{
Literature Review of Comparative Islamic Literature's Idea of \\ Sayyid Sayyid 'Abd al-Raziq and Mohd Affandi Hassan
}

\author{
MOHD ADI AMZAR MUHAMMAD NAWAWI*, ZULKARNAIN MOHAMED \& \\ PABIYAH TOKLUBOK @HAJIMAMING ${ }^{1}$
}

\begin{abstract}
Difference of views in understanding the idea of Islamic literature and criticism involves two different cultures often occur in the field of comparative literature world. Yet despite the differences and inequalities, still no agreement reached involving key issues in the discussion of the concept of Islamic literature. Thus, this paper aims to highlight the previous studies related to the ideas, theories and principles of Islamic literature, the examples of comparative literature study and leaders thought. Analysis of the literature is conducted to find justification for the study and comparison of ideas on the need of dismantling the Islamic literature involving two selected leaders, Sayyid Sayyid Abd al-Raziq and Mohd Affandi Hassan. This is a qualitative study based on applied content analysis method. This literature review finds that the application of this comparative study is able to find the special formula in identifying similarities and differences in the concept of Islamic literature and criticism involving the two leaders while providing enlightenment to the players in this field.
\end{abstract}

Keywords: Islamic literature, Mohd Affandi Hassan, Sayyid Sayyid `Abd al-Raziq

Istilah 'kesusasteraan Islami' dalam kalangan penggiat dan penggemar dalam bidang kesusasteraan mungkin jarang didengari dan diberi perhatian sebelum ini lantaran fikiran sebahagian daripada kita yang telah dimomokkan dengan pelbagai idea dan teori-teori Barat yang bersifat gah tetapi rupanya racun yang memakan diri secara perlahan. Masakan tidak ketika dunia kesusasteraan sedang bermegah-megah dengan penghasilan karya dan teks sastera yang bersandarkan kepada teori-teori pelik ciptaan Barat, kita masih berpolemik dan berperang atas kerancuan fikiran sesama kita dalam menentukan idea dan falsafah sastera Islami sehingga terlupa perkara penting yang perlu diutamakan terlebih dahulu. Polemik sastera Islami antara Shahnon Ahmad dan Kassim Ahmad sekitar awal 80-an sejujurnya bukanlah sesuatu yang enak untuk diperbahaskan tetapi rentetan daripada peristiwa tersebut

\footnotetext{
${ }^{1}$ Mohd Adi Amzar Muhammad Nawawi*(Corresponding author), Ph.D. candidate at Dept. of Arabic Studies and Islamic Civilization, Faculty of Islamic Studies, Universiti Kebangsaan Malaysia 43600 BANGI, Selangor, Malaysia, email: gamwer_994@yahoo.com.my; Zulkarnain Mohamed, Ph.D., Senior Lecturer at Dept. of Arabic Studies and Islamic Civilization, Faculty of Islamic Studies, Universiti Kebangsaan Malaysia 43600 BANGI, Selangor, Malaysia, email: nain@ukm.edu.my; Pabiyah Toklubok @Hajimaming, Ph.D., Senior Lecturer at Dept. of Foreign Languages, Faculty of Modern Languages and Communications, Universiti Putra Malaysia, SERDANG, Selangor, Malaysia, email: pabiyah@upm.edu.my.
} 
seolah-olah telah membuka mata ramai pihak untuk menyedari akan kehadiran sastera Islami khususnya di bumi Malaysia dan memberi banyak faedah kepada penggiat dalam lapangan kesusasteraan kemudiannya. Ini dapat dibuktikan dengan pemurnian falsafah dan intipati sastera Islami itu sehingga telah wujud pelbagai idea, teori dan gagasan tersendiri dalam mengolah konsep sastera Islami agar dapat dikembangkan dan dihayati oleh khalayak. Ini dapat dilihat dengan kemunculan teori Takmilah oleh Shafie Abu Bakar, teori Ta`abudiah dan Teksdealisme ciptaan Mana Sikana, gagasan Persuratan Baru oleh Mohd Affandi Hassan dan lain-lain lagi.

Walaupun wacana sastera Islami di Malaysia mengalami perkembangan yang positif dari semasa ke semasa namun sesuatu yang perlu diketahui ialah sebahagian daripada pelopor di Malaysia terpengaruh dengan idea atau gagasan yang dibawa oleh tokoh-tokoh kesusasteraan Islami dari Timur Tengah yang terlebih dahulu membangkitkan persoalan dan polemik mengenai sastera Islami sehingga menjalar perbahasannya ke Nusantara Melayu. Ini dapat dilihat dengan sebahagian tokoh di Malaysia seperti Shafie Abu Bakar, Mohd Kamal Hassan dan beberapa tokoh yang lain terpengaruh dengan idea yang dibawa Sayyid Qutb dan adiknya, Muhammad Qutb (Adli Yaacob 2007). Kemunculan beberapa tokoh dari Timur Tengah yang telebih dahulu mewarnai kerancakan dalam pembinaan tasawur kesusasteraan Islami seharusnya tidak boleh dilupakan antaranya Sayyid Qutb sebagai pencetus kepada idea ini, Muhammad Qutb, 'Imaduddin Khalil, Abdul Hamid Buzawainah, Abdul Mun im Khafaji, Syeikh Abu Hassan Ali al-Nadwi yang merupakan seorang ulama terkemuka kelahiran India, Sayyid Sayyid 'Abd al-Raziq dan lain-lain nama besar lagi.

Sumbangan para pemikir dan tokoh dari dua kebudayaan yang berlainan iaitu Arab dan Melayu khususnya dalam pembinaan idea, gagasan dan metodologi kritikan sastera Islami adalah sesuatu yang wajar diberi perhatian. Justeru, fokus kajian sorotan literatur ini ingin membawa pembaca menelusuri dua orang tokoh yang dipilih iaitu Sayyid Sayyid `Abd al-Raziq yang mewakili pemikir dari Timur Tengah dan Mohd Affandi Hassan dari Malaysia. Walaupun terdapat pelbagai idea ataupun teori yang berkaitan dengan idea gagasan dan kritikan sastera Islami yang telah diperkenalkan dan dibahaskan oleh para pengkaji dan pengkritik dalam lapangan kesusasteraan Islami dahulu dan terkemudian, namun teori janaan Mohd Affandi Hassan berkaitan dengan konsep taklif dan gagasan Persuratan Baru (Genuine Literature) telah membuka dimensi baru yang lebih luas berkaitan dengan falsafah kesusasteraan Islami dan metodologi Islam dalam mengkritik karya sastera. Kewujudan pemikiran beliau juga adalah bersifat semasa dan kotemporari setelah menilai kembali perbahasan-perbahasan oleh ilmuwan lampau pada dekad-dekad terdahulu. Jika dilihat kepada sumbangan Mohd Affandi Hassan khususnya dalam dunia kesusasteraan Islami di Malaysia, ternyata pengenalan kepada karya pertama beliau yang membicarakan mengenai konsep taklif dalam Pendidikan Estetika daripada Pendekatan Tauhid adalah sesuatu yang sangat menjangkaui pemikiran para penggiat kesusasteraan ketika itu. Penerapan unsur tauhid melalui tiga ciri utama iaitu hakikat insan, hakikat ilmu dan amal serta hakikat dan fungsi sastera yang merupakan kunci kepada pemikiran beliau telah membawa khalayak memahami dengan lebih jelas mengenai fungsi sastera Islami itu sendiri lantas menenggelamkan fahaman dan ideologi Barat yang membelenggu pemikiran para pengkarya ketika itu. Juga, lanjutan kepada penghasilan novel rangkaian iaitu Pujangga Melayu sebagai magnum opus utama beliau dalam memberikan pilihan alternatif kepada khalayak dalam memilih karya-karya yang menjiwai sastera Islami dengan sebenarnya.

Ketokohan Sayyid Sayyid `Abd al-Raziq juga tidak kurang hebatnya meskipun tidak segah seperti Muhammad Qutb, Imad al-Din Khalil dan lain-lain. Walaupun demikian, kejayaan Sayyid Sayyid Abd al-Raziq dalam memenangi anugerah inovasi kritikan sastera pada tahun 2001 oleh Dar al-Fikr adalah sesuatu yang memberikan kelebihan dan bonus untuk dirinya 
untuk muncul sebagai pelopor baru dalam dunia kesusasteraan Islami moden bagi dunia Arab khususnya. Ini berikutan pengiktirafan Dar al-Fikr yang berpusat di Damascus, Syria itu yang mengiktiraf penghasilan sebuah buku yang dikarang oleh al-Raziq yang bertajuk Manhaj alIslam fi al-Naqd al-Adabi yang dilihat banyak memberikan pendedahan dan konsep yang lebih bersifat segar dalam dunia sastera Islami dan kritikan. Beliau juga banyak menghasilkan artikelartikel yang dimuatkan dalam jurnal dan banyak membentangkan kertas kerja berkaitan sastera Islami di persidangan-persidangan antarabangsa.

Oleh itu, kewujudan teori ataupun idea yang berlegar dalam pemikiran kedua-dua tokoh tersohor ini perlu untuk dirungkai dan disingkap agar kehebatan pemikiran mereka dapat diambil manfaat dan dijadikan ikutan oleh para penggiat kesusasteraan yang lain. Di samping itu, kajian ini dapat menambah koleksi literatur yang sedia ada dan mengatasi kelompangan kajian terutama yang membabitkan kedua-dua orang tokoh ini. Oleh demikian, pada bahagian seterusnya, kajian ini akan menelusuri secara mendalam dan kritis mengenai perbahasan gagasan sastera Islami secara umum dan berkaitan dengan kedua-dua tokoh ini secara khusus melalui sorotan literatur yang dilakukan terhadap literatur-literatur yang terpilih dan yang berkaitan dengan isu yang dikaji dalam kajian ini. Di harap melalui sorotan literatur ini dapat mewujudkan satu percambahan ilmu yang baru serta dapat mengisi kelompangan kajian sekaligus dapat menyerlahkan kepentingan kajian ini agar dapat dilaksanakan dengan jayanya.

\section{Sorotan Literatur}

Dalam membahaskan sorotan literatur mengenai perbandingan pemikiran gagasan sastera Islami antara Sayyid Sayyid 'Abd al-Raziq dan Mohd Affandi Hassan, terdapat beberapa isu yang menjadi perhatian dan memerlukan penelitian yang lanjut dalam kajian ini. Antara isu yang menjadi perhatian ialah kewujudan aliran pemikiran yang pelbagai antara tokoh dan ilmuwan Arab dan Melayu terhadap falsafah sastera Islami dan bagaimana perbezaan ini mampu memberikan keuntungan yang saling tidak merugikan antara satu sama lain. Selain itu juga, isu yang akan diketengahkan ialah kepentingan kajian kesusasteraan bandingan antara dua kebudayaan atau tempat yang berbeza dalam menghasilkan satu paradigma berfikir dan pendekatan yang seakan-akan seperti berbeza namun hakikatnya ia saling lengkap-melengkapi antara satu sama lain. Justeru itu, bagi melancarkan perbahasan sorotan literatur ini, kajian ini akan membahagikan perbahasan kepada dua sub topik iaitu gagasan dan kritikan terhadap sastera Islami serta yang kedua contoh kajian yang berkaitan dengan kesusasteraan bandingan dan kajian pemikiran mengenai tokoh yang dikaji dalam sorotan literatur ini. Bagi mendapat hasil lanjut dan analisis, kajian ini telah meneliti dan menganalisis sorotan literatur-literatur yang berkaitan bagi menguatkan hujah dan mengukuhkan pendirian asal kepada kerelevenan kajian ini dilakukan bagi mengenal pasti gagasan sastera Islami terhadap pemikiran kedua-dua orang tokoh berlainan kebudayaan berdasarkan disiplin kesusasteraan bandingan. Seperti yang dimaklumkan, perbahasan sorotan literatur akan dicerakinkan kepada dua sub topik iaitu idea, teori, dan prinsip sastera Islami serta yang kedua iaitu contoh kajian yang berkaitan dengan kesusasteraan bandingan dan pemikiran mengenai tokoh yang dikaji dalam sorotan ini.

\section{Gagasan dan Kritikan Terhadap Sastera Islami}

Sebelum membicarakan dengan lebih terperinci gagasan dan kritikan terhadap sastera Islami, persoalan asas yang perlu untuk diperhalusi semula oleh semua golongan yang terlibat dalam lapangan kesusasteraan Islami adalah bagaimana untuk mewujudkan sebuah karya sastera yang layak diangkat sebagai sastera Islami dan memenuhi ciri-ciri sebagai sebuah karya yang sarat dengan ilmu dan mendidik jiwa. Ini kerana sastera Islami dan etika dalam pengkaryaan 
merupakan satu hubungan yang berkait rapat antara satu sama lain. Kesamaran dan kekaburan terhadap falsafah sastera Islami akan mengakibatkan refleksi dalam karya bernada negatif dan menghina Islam. Begitu juga sebaliknya apabila pemanfaatan pengkarya tidak berpaksikan kepada ilmu daripada falsafah sastera Islami sebenar akan mengundang pentafsiran yang mempersoalkan kesucian Islam secara tidak sedar. Hakikat yang perlu disedari, persoalan ini bukanlah mudah untuk ditanggapi kerana pandangan pengkarya terhadap sastera Islami melibatkan pelbagai pentafsiran dan pandangan yang berbeza. Keadaan ini sedikit sebanyak merencatkan proses pemurnian falsafah sastera tersebut ke arah yang lebih bersepadu. Walaupun demikian, kritikan dan cadangan pembaharuan oleh golongan sarjana dalam bidang kesusasteraan Islami khususnya terhadap pemurnian falsafah sastera Islami mempunyai kewajaran yang perlu untuk diberikan ruang agar falsafah dan konsep sastera itu sentiasa bersifat terbuka dan segar malahan tidak terkeluar daripada landasan yang digariskan oleh agama.

Terdapat kajian oleh Imad al-Din Khalil (1998) yang membahaskan mengenai satu penilaian semula mengenai gerakan sastera Islami kontemporari adalah sesuatu yang wajar diberikan perhatian oleh golongan sasaran yang berkaitan. Beliau telah memperincikan beberapa isu yang menjadi permasalahan kepada kebangkitan semula gerakan ini sehingga ditenggelamkan oleh aliran dan fahaman Barat yang menyeleweng. Beliau memberi penekanan bahawa perlunya perubahan secara besar-besaran terhadap bentuk dan kandungan dalam karya sastera Islami itu yang selama ini dilihat kabur dan tidak jelas. Di samping itu, beliau mempersoalkan bahawa metodologi sastera Islami semakin kehilangan identiti sehingga dianggap sebagai penanda aras sahaja dan bukannya satu aliran mazhab dalam kesusasteraan. Beliau membandingkan dengan kewujudan aliran-aliran selain daripada Islam seperti sosialisme, romantisme, realisme dan lain-lain yang mendominasi pemikiran pengkarya Muslim dalam lapangan kesusasteraan. Buat akhirnya, beberapa penyelesaian dicadangkan bagi mengukuhkan kembali gerakan sastera Islami antaranya merangka garis panduan berlandaskan Syariah kepada pengkarya Muslim untuk menghasilkan karya sastera Islami yang berakarkan kefahaman Islam yang sebenar. Selain itu, pertubuhan dan pusat-pusat pengajian perlu diaktifkan secara optimum untuk memberi kefahaman yang holistik kepada pengkarya bagi menghasilkan karya yang berkualiti dan bernada positif.

Bin Isa Batahir (1998) telah memperkemaskan takrifan falsafah kritikan dan sastera Islami ke arah yang lebih mudah difahami. Kajian beliau yang bertajuk Pandangan Syeikh Abu Hasan al-Nadwi berkaitan Sastera Islami dan Kritikan telah menghuraikan takrifan sastera Islami, fungsi dan perkaitannya dengan hiburan dengan lebih terperinci. Beliau juga menjelaskan pandangan Syeikh Abu Hasan al-Nadwi mengenai kritikan sastera yang mencakupi pengakaran Islam terhadap kritikan, fungsi kritikan Islam dan sifat sebagai pengkritik Muslim. Artikel setebal 30 halaman ini memperlihatkan takrifan konsep sastera Islami yang lebih bersifat dinamik dengan memasukkan dua elemen iaitu ikhlas dan benar sebagai nadi utama yang memperhebatkan lagi keindahan sastera Islami itu di samping menyerlahkan keperluan untuk mengakarkan kritikan yang berlandaskan Islam. Ini kerana teori kritikan adalah bersumberkan daripada Barat dan menjadi keperluan untuk mengembalikan akar tradisi kritikan Islam bagi menghidupkan kembali roh kesusasteraan Islam yang telah diselewengkan sejak sekian lama.

Kajian Imad al-Din Khalil (2009) juga telah membangkitkan isu yang sama mengenai kedudukan sastera Islami pada era kontemporari ini. Makalah beliau yang bertajuk Intipati Pemikiran Sastera Islami Kontemporari telah mempersoalkan kredbiliti sastera Islami yang seolah-olah telah hilang metodologinya yang tersendiri dan hanya dianggap sebagai satu garis panduan serta bukan berdiri atas satu aliran khas. Selain itu, wujud pertembungan antara golongan sasterawan dan agamawan yang sedikit sebanyak telah menambahkan kecelaruan 
terhadap identiti sastera Islami itu. Ini kerana sesetengah golongan sasterawan lebih cenderung menghalalkan sesuatu perkara dengan tergesa-gesa tanpa merujuk terlebih dahulu kepada golongan agamawan yang lebih mengetahui tentang selok-belok hukum khususnya yang melibatkan bidang kesenian dan sastera. Ini berlaku disebabkan kejahilan sesetengah golongan sasterawan yang memandang enteng mengenai hukum hakam sehinggakan tindak-tanduk mereka dilihat sebagai membelakangkan dan menghina agama. Gesaan penulis pada akhir makalah beliau dengan jelas menegaskan bahawa perlunya usaha berganda demi memastikan sastera Islami kembali kepada pengakaran Islam yang sebenar di samping membentuk satu metodologi khas dalam kritikan sastera sebagaimana yang dilakukan oleh aliran atau mazhab kesusasteraan selain Islam.

Selain itu, kajian al-Rahawi (2009) juga telah memberi satu penjelasan yang kukuh mengenai falsafah pemaknaan sastera Islami dan peranannya. Kajian beliau yang berkisar mengenai sastera Islami antara makna deskriptif dan peranan telah membahaskan peranan yang perlu dimainkan oleh pengkarya dalam menghasilkan teks-teks yang berunsurkan agama bagi memenuhi piawaian sebagai karya sastera Islami. Beliau menegaskan perlunya seseorang pengkarya itu memahami Islam secara keseluruhannya dan mengaplikasikan ke dalam karya dalam bentuk yang tidak menghina roh agama. Islam tidak menghalang seseorang itu untuk berkarya secara kreatif tetapi mestilah dalam lingkungan yang dibenarkan agama. Ini kerana kebebasan untuk berkarya bukanlah hak mutlak bagi seseorang manusia di muka bumi kerana segala perlakuannya nanti akan dipertanggungjawabkan kelak di hadapan Allah. Beliau juga menegaskan peranan sastera Islami bukan sahaja untuk menjadi alternatif kepada aliran sastera yang lain bahkan jauh daripada itu untuk bertindak sebagai agen yang membawa risalah dakwah Islam kepada manusia keseluruhannya.

Keunggulan dan kehebatan sesebuah karya sastera Islami bukan hanya terletak kepada bentuk atau aturan huruf perkataan mahupun ayat dalam karya tersebut bahkan menjangkaui kepada perwatakan dan komitmen seseorang pengkarya Muslim itu. Ini semestinya berkait rapat dengan persoalan prinsip kritikan sastera Islami yang menjadi persoalan utama yang dibahaskan dalam sorotan literatur ini. Selepas meneliti perbahasan awal mengenai sastera Islami, prinsip sastera Islami dan kritikannya menjadi tumpuan untuk perbahasan selanjutnya dengan memberi penekanan terhadap istilah-istilah yang berkait rapat dengan idea kritikan seperti iltizam, ta amul, taklif dan perbahasan mengenai etika menganalisis al-Quran dan Hadith.

Istilah iltizam merupakan antara istilah yang telah lama wujud dalam kesusasteraan pada zaman peradaban tamadun lampau seperti Mesir Kuno, Yunani, Rom dan Arab Jahiliyah. Namun begitu, persoalan iltizam mendapat perhatian secara mendalam selepas kelahiran pelbagai aliran kesusasteraan moden seperti dalam aliran realisme sosialisme dan aliran eksistensialisme. Dalam aliran sastera Islami juga tidak ketinggalan dalam membincangkan mengenai persoalan iltizam secara lebih mendalam dan berfokus. Ini dapat ditelusuri melalui kajian yang dilakukan oleh 'Abd al-Raziq (2009) dalam makalah beliau yang bertajuk Istilah Iltizam dalam Kritikan Islam Semasa: Kajian Terhadap Pemahaman dan Ruang Pengaplikasian. Pada permulaan makalah ini, beliau telah mengupas secara mendalam mengenai perbezaan intipati pada istilah iltizam yang digunakan oleh aliran kesusasteraan selain Islam seperti aliran realisme sosialisme dan eksistensialisme yang lebih bersifat material dan keduniaan. Ini kerana iltizam menurut aliran realisme sosialisme ialah kemampuan seseorang pengkarya berpaksikan kepada realiti dan bukan khayalan semata-mata dalam menghasilkan karya manakala aliran eksistensialisme lebih menumpukan idea seseorang pengkarya dalam menentukan sepenuh pendiriannya terhadap masalah dan isu yang berlaku sekitarnya. Beliau menegaskan lagi bahawa menurut konteks sastera Islami, iltizam adalah idea yang diambil daripada fahaman lain tetapi masih boleh disesuaikan mengikut acuan Islam. Ini terbukti dengan penegasan oleh Najib 
Kailani yang mengatakan bahawa iltizam bagi sastera Islami adalah dengan seseorang pengkarya muslim itu bertanggung jawab terhadap segala apa yang diungkap dan dilakukan serta melazimi dengan metodologi Islam yang syumul khususnya ketika berkarya. Penulis makalah ini juga menggariskan beberapa ciri-ciri iltizam menurut sastera Islami antaranya pengkarya itu mestilah mempunyai metodologi yang jelas dan tidak melampaui batasan terhadap pegangannya di samping tidak melampaui had kebebasan yang dibenarkan oleh agama.

Persoalan iltizam dalam kesusasteraan Islam dirungkai dengan lebih meluas lagi oleh Mujahid Mustafa Bahjat (2009) dalam makalah beliau yang bertajuk Keindahan dan Iltizam dalam Seni Islam. Secara keseluruhannya, makalah setebal 28 halaman ini menyentuh tiga topik asas iaitu perkaitan Islam dengan keindahan, pandangan kritikan Islam terhadap pemahaman iltizam serta kajian gaya bahasa al-Quran dari aspek keindahan lafaz dan ketinggian makna. Beliau menegaskan bahawa keindahan daripada pandangan Islam tersangat luas dan merangkumi banyak perkara sama ada dalaman atau luaran. Islam juga sangat mementingkan keindahan dan kesempurnaan secara zahir seperti kukuh dan lurusnya barisan perajurit yang sedang bertempur di medan perang melawan musuh. Bagi pandangan kritikan Islam terhadap iltizam, beliau menggariskan perlunya seseorang pengkarya itu mempunyai pengetahuan khusus mengenai al-Quran dan hukum-hakam syariat bagi memandu agar tidak terpesong daripada batasan yang dibenarkan. Islam mengalu-alukan dan sama sekali tidak menyekat kebebasan seseorang untuk berkarya, namun biarlah kebebasan berkarya itu dipandu dengan roh dan kefahaman dalam rangka fundamental Islami yang sebenar. Beliau menegaskan buat akhirnya bahawa melakukan sesuatu perkara yang membatasi syariat agama adalah sesuatu yang bersalahan dengan roh Islam melainkan jika dipandu dengan asas-asas akhlak yang mulia, elemen ketanggung jawaban dan prinsip iltizam yang menjadi nadi utama ketika berkarya. Makalah ini secara umum banyak memberikan percambahan ilmu khususnya perkaitan penting yang menghubungkan antara konsep keindahan dan iltizam melalui kacamata tauhid daripada skala yang besar.

Idea ataupun prinsip kritikan sastera Islami pada era moden kini dapat dilihat seterusnya menerusi konsep ta amul yang diperkenalkan oleh 'Abd al-Raziq (2002). Beliau telah memerihalkan konsep ta'amul ini dalam sebuah buku yang bertajuk Metodologi Islam Terhadap Kritikan Sastera. Menurutnya, idea untuk menghasilkan konsep ini timbul apabila melihat para pengkritik sastera lebih gemar menggunakan teori kritikan yang berasaskan Barat dan ini akan menyebabkan berlaku kepincangan dan ketidak seimbangan ketika mengkritik sesebuah karya sastera Islami. Sewajarnya menurut beliau lagi perlunya sebuah metodologi khas yang disusun dengan sistematik mengenai pandangan Islam ketika berurusan dan mengkritik sesebuah karya. Menyentuh mengenai kandungan buku, beliau telah menggariskan beberapa panduan dan langkah khususnya ketika berurusan dengan bahan yang bersumberkan Islam sepenuhnya seperti al-Quran, Hadith dan bahan yang bersumberkan selain Islam seperti bahan-bahan pada zaman Arab Jahiliyah, tamadun moden dan purba seperti tamadun Mesir, Greek, Rom, Parsi, Hindu dan lain-lain. Walaupun perbahasan dalam buku ini ada melibatkan tatacara berurusan dengan sumber selain Islam, pengkaji lebih berminat untuk menumpukan kepada perbahasan mengenai tatacara berurusan dengan sumber Islam di mana mempunyai kaitan langsung dengan persoalan yang sedang dibahaskan dalam sorotan literatur ini. Dalam perbahasan mengenai tatacara berurusan dengan sumber Islam, penulis buku menegaskan tentang peri pentingnya menjadikan dua sumber tertinggi dalam Islam iaitu al-Quran dan Hadith sebagai sumber perlembagan dan rangka ilmu untuk mengkritik. Selain itu, beliau mencadangkan keperluan yang utama untuk menjadikan gaya bahasa retorika al-Quran dan Hadith sebagai pengungkapan yang terbaik untuk diabadikan dalam karya sastera kerana nilai retorika keduadua sumber tertinggi Islam ini tiada bandingannya. Beliau juga menjelaskan karya yang 
berteraskan Islam adalah dengan mengaplikasikan ciri-ciri Islam yang telah disepakati oleh alim ulama dan menghasilkan sesuatu yang unik tetapi masih selaras dengan metodologi Islam yang telah diperakui.

Seterusnya, idea khusus mengenai prinsip kritikan sastera Islami dapat dilihat menerusi nukilan Mohd Affandi Hassan (2005) dalam karyanya yang bertajuk Pendidikan Estetika daripada Pendekatan Tauhid. Beliau telah membahaskan persoalan etika dan tanggungjawab dengan perbahasan menarik yang mencakupi aspek falsafah, kaedah dan pendekatan dalam menghasilkan sastera yang berteraskan Islam. Daripada aspek falsafah, beliau telah menekankan kepentingan peranan pengkarya dalam menghasilkan karya yang bersifat didaktik dan kewajipan menghayati tiga hakikat yang menjadi teras dalam persoalan ketanggungjawaban iaitu hakikat insan, hakikat ilmu dan amal, dan hakikat serta fungsi sastera. Hasil reaksi seseorang pengkarya dalam menghayati ketiga-tiga hakikat ini akan mewujudkan kesedaran 'taklif iaitu merupakan ketanggungjawaban seseorang manusia yang memikul peranan selaku khalifah di muka bumi ini untuk menyebarkan agama Allah. Garapan idea berhubung dengan persoalan etika yang ditonjolkan oleh Mohd Affandi Hassan dalam makalah ini secara tidak langsung banyak membuka dimensi baru dalam penambahbaikan metodologi kritikan yang berakarkan Islam yang tulen. Ini kerana rumusan idea taklif yang bertitik tolak daripada tiga hakikat utama yang diperkenalkan oleh beliau mencambahkan pemikiran baharu dan unik khususnya dalam memahami sastera Islami yang sebenar seperti contoh idea beliau yang menolak konsep mimesis atau fictionality yang menjadi keagungan Barat dan budaya sekular.

Mohd Shahrizal Nasir \& Mohd Firdaus Yahaya (2013) juga ada menulis sebuah makalah yang merakamkan idea taklif secara tidak langsung. Makalah yang bertajuk Peranan Novelis Muslim dalam Usaha Menyebar Al-Ma'ruf dan Menyekat Al-Mungkar telah menyenaraikan beberapa panduan dan langkah dalam menyebarkan al-ma'ruf dalam dunia penulisan karya antaranya seperti menyebarkan isi kandungan al-Quran, mengutamakan ilmu daripada cerita serta menjadikan al-Quran sebagai panduan dalam berkarya. Para penulis juga mencadangkan dua langkah yang boleh diambil bagi menyekat al-mungkar dalam dunia kesusasteraan kreatif seperti tidak menulis perkara bertentangan dengan ketetapan Islam dan menolak sebarang bentuk elemen yang menghina Islam. Secara keseluruhannya, makalah ini boleh disifatkan sebagai penghuraian konkrit dalam bentuk aplikasi kepada idea taklif yang dijana oleh Mohd Affandi Hassan. Ini kerana idea yang dirumuskan oleh kedua-dua penulis dalam makalah ini menjadikan al-Quran sebagai paksi dan idea utama dalam mengemukakan panduan ketika berkarya dan ini bertepatan dengan objektif sastera Islami iaitu mengagungkan kalamullah secara langsung.

Setelah meneliti perbahasan sorotan literatur terhadap konsep sastera Islami dan lainlain, perbahasan sorotan pada bahagian pertama ini akan melihat kepada idea kritikan terakhir yang bertunjangkan sastera Islami iaitu teori menganalisis al-Quran dan Hadith. Secara keseluruhannya, terdapat dua kajian yang berkaitan dengan idea dan teori menganalisis alQuran dan Hadith dari sudut pandang sastera iaitu kajian yang dilakukan oleh Zulkarnain Mohamed (2010, 2009). Kajian beliau (2010) yang bertajuk Al-Quran, Ilmu, Disiplin Islam dan Sastera lebih membincangkan mengenai status al-Quran sebagai sumber ilmu yang paling agung dalam Islam termasuk perbahasan al-Quran sebagai wahyu dan mukjizat. Di samping itu, penulis juga telah memperincikan hubungan Al-Quran dengan sastera Islami dengan penekanan kepada dua istilah peminjaman rangka cerita yang bersumberkan al-Quran iaitu istinbat dan iqtibas. Penggunaan kedua-dua istilah ini dengan nada positif akan menghasilkan karya yang tidak menghina Islam dan selaras dengan etika dan akhlak Islamiah. Penulis juga ada memperincikan mengenai teori pemanfaatan keindahan al-Quran antaranya seperti menjaga nada keindahan kalamullah dengan menghindari nada sinis, menghina dan juga memahami 
konsep-konsep al-Quran melalui tafsir yang muktabar. Makalah ini secara umumnya banyak membantu pengkaji memahami mengenai asas-asas pemanfaatan al-Quran dan tatacara berurusan dengan kitab suci terhadap karya sastera.

Selanjutnya, kajian yang berkaitan di atas juga telah dinukilkan oleh Zulkarnain Mohamed (2009) dalam makalah lain yang bertajuk Etika Menganalisis Al-Quran dan Hadith dari Sudut Sastera. Dalam kajian ini, beliau telah memperincikan cara-cara menganalisis alQuran dan Hadith dengan beretika dan berakhlak dengan memberi penumpuan terhadap struktur dialektika kedua-dua sumber tertinggi ini. Rumusan akhir beliau dengan jelas meletakkan retorika al-Quran sebagai panduan etika keseluruhan kesusasteraan Islami diikuti dengan retorika Hadith dan tradisi retorika Arab Islami. Hasil sintesis dan analisis terhadap ketiga-tiga unsur di atas akan melahirkan idea falsafah, teori dan aplikasi sastera yang bersifat mapan dan komprehensif.

\section{Contoh Kajian Kesusasteraan Bandingan dan Pemikiran Tokoh}

Pada bahagian sub topik yang kedua ini, perbahasan sorotan literatur akan meninjau contohcontoh kajian yang berkaitan dengan kesusasteraan bandingan dan pemikiran tokoh yang dikaji dalam sorotan ini iaitu Sayyid Sayyid 'Abd al-Raziq dan Mohd Affandi Hassan. Secara keseluruhannya banyak kajian kesusasteraan bandingan yang ditemui membicarakan mengenai perbandingan antara dua tokoh terhadap sesuatu isu atau gagasan seperti kajian Rahmah Ahmad \& Mohd Shahrizal Nasir (2011), kajian Mohd Faizal Musa (2010) dan kajian Adli Yaacob (2006) yang lebih menumpukan perbandingan terhadap isu gagasan sastera Islami. Selain itu, kajian kesusasteraan bandingan yang lain adalah seperti kajian Pabiyah Hajimaming (2007), Kathirasan (2004), Ahmad Redzaudin (2005), Mohd Zulkifli (2010) dan Md Nor (2014). Manakala kajian yang melibatkan pemikiran tokoh adalah seperti kajian Wan Zaida (2010), R. Sharatha (2007) dan Mohd Zariat (2004) yang menumpukan kepada pemikiran Mohd Affandi Hassan berdasarkan kepada karya-karya yang telah beliau hasilkan. Setakat pengamatan yang dilakukan, tidak menemui lagi kajian ilmiah yang membahas dan membicarakan mengenai Sayyid Sayyid Abd al-Raziq dan ini seharusnya menjadi pemangkin kepada kajian ini untuk dilakukan memandangkan beliau juga antara merupakan tokoh kesusasteraan Islami yang banyak menyumbangkan idea dan pemikiran yang bernas ke arah pembinaan tasawur dan metodologi kritikan sastera Islami yang bersifat holistik.

Antara kajian kesusasteraan bandingan yang membahaskan gagasan sastera Islami adalah kajian yang dilakukan oleh Rahmah Ahmad \& Mohd Shahrizal Nasir (2011) yang bertajuk Sastera Islam: Satu Perbandingan antara Pandangan Mohd Affandi Hassan dengan Abu al-Hasan Ali al-Nadwi. Secara keseluruhannya, artikel setebal 40 halaman ini membicarakan mengenai gagasan sastera Islami menurut sudut pandang daripada dua orang tokoh berlainan negara dan kebudayaan yang berbeza iaitu daripada Malaysia dan India. Ini dapat ditelusuri menerusi pandangan Mohd Affandi Hassan melalui idea gagasan beliau yang terkenal iaitu Persuratan Baru telah merungkai rahsia falsafah sastera Islami secara halus dan terperinci melalui pendekatan tauhid dengan tiga teras utama iaitu hakikat insan, hakikat ilmu dan amal, dan hakikat serta fungsi sastera. Manakala sastera Islami menurut pandangan al-Nadwi yang juga merupakan mantan pengerusi Pertubuhan Sastera Islam Sedunia menggariskan empat ciri utama yang membangunkan sastera Islami itu iaitu hubungan sastera dengan kehidupan, hubungan sastera dengan Islam, sastera Islam adalah sastera yang luas dan yang terakhir sastera Islam adalah sastera yang membina. Walaupun pada hakikatnya mereka berdua berasal daripada kebudayaan yang berbeza namun mereka sependapat dalam menyatakan bahawa kandungan dalam pengkaryaan sastera mestilah lebih mengutamakan mesej dan ilmu daripada penceritaan semata-mata. Mereka juga bersepakat bahawa perlunya pengiktirafan dan 
perhatian diberikan terhadap karya-karya klasik lama yang terlebih dahulu mewarnai dunia kesusasteraan dengan ilmu berbanding dengan kesusasteraan moden kini yang lebih banyak menawarkan isian cerita yang kosong dengan ilmu dan kebenaran.

Kajian Mohd Faizal Musa (2010) yang bertajuk Sastera Islam: Fenomena, Wacana dan Penerapannya di Malaysia dan Indonesia juga menampilkan disiplin bandingan dalam memahami sastera Islam melalui pendekatan fenomena, wacana dan penerapan yang diamalkan di Malaysia dan Indonesia. Kajian beliau telah mengaplikasikan kerangka analisis bandingan model supra nasional yang disarankan oleh Claudio Guillen di mana perlunya wujud 'hubungan genetik' antara pengarang yang berasal dari titik tolak budaya dan sudut kebangsaan yang sama. 'Hubungan genetik' yang dimaksudkan dalam kajian beliau ini adalah perkaitan aspek ilmu, akhlak dan tauhid yang dirungkaikan melalui tiga buah novel sastera Islam dari Malaysia dan tiga buah novel sastera Islam dari Indonesia. Analisis perbandingan dalam kajian ini melibatkan novel Pujangga Melayu (Malaysia) karya Mohd Affandi Hassan dan Kedai Sufi Kang Luqman (Indonesia) oleh Mohd Lukman Hakim daripada aspek ilmu, novel Tivi (Malaysia) karya Shahnon Ahmad dan Ayat-Ayat Cinta (Indonesia) karya Habiburrahman El Shirazy daripada aspek akhlak dan yang terakhir novel Khotbah di Atas Bukit (Indonesia) karya Kuntowijoyo dan Salam Maria (Malaysia) oleh Fatimah Busu daripada aspek tauhid. Penulis juga menggunakan Al-Quran dan Al-Sunnah sebagai skema nilai terbesar dalam merungkaikan teks yang mana memperlihatkan perbezaan yang ketara dalam pendekatan menggubah karya antara para novelis kedua-dua buah negara. Perbezaan ini wujud lantaran wacana dan penerapan sastera Islam di Indonesia lebih cenderung ke arah sufisme berbanding wacana dan penerapan di Malaysia yang lebih melihat 'Islam atau tidak Islamnya' sesebuah karya. Kajian ini juga secara jelas telah membuktikan bahawa perbezaan pemikiran dan idea mengenai sesuatu isu masih wujud walaupun masih berada dalam lingkungan kebudayaan yang hampir sama.

Kajian perbandingan seterusnya mengenai gagasan sastera Islami telah dilakukan oleh Adli Yaacob (2006) dengan fokus kajian beliau adalah kepada perbandingan pengertian sastera Islami di kalangan sasterawan Arab dan Melayu pada era moden. Tesis yang dihasilkan oleh beliau untuk memperolehi ijazah Doktor Falsafah ini telah menghasilkan banyak penemuan khususnya melibatkan perkaitan secara langsung antara pengaruh kebudayaan Arab terhadap kebudayaan Melayu Islam. Dalam memperjelaskan perkaitan pengaruh antara kedua-dua kebudayaan ini, penulis terlebih dahulu menyoroti kajian dengan membahaskan perkembangan awal sastera Islami pada zaman permulaan Islam dan diikuti oleh zaman Umawiyyah, Abbasiyah dan era moden. Kemudian beliau memaparkan intipati utama gagasan sastera Islami daripada setiap tokoh terkenal dari dunia Arab seperti Muhammad Qutb, 'Imad al-Din Khalil, Najib Kailani, `Abd Hamid Buzawaynah dan juga tokoh daripada Malaysia seperti Syed Muhammad Naquib al-Attas, Mohd Affandi Hassan, Shafie Abu Bakar, Mana Sikana dan lain-lain lagi. Dengan menggunakan metodologi pensejarahan deskriptif dan analisis bandingan terhadap dua kelompok berbeza iaitu Arab dan Melayu, penulis mendapati wujud banyak titik persepakatan mengenai pengertian sastera Islami daripada kedua-dua kelompok ini antaranya sastera Islami adalah bersumberkan terus daripada Al-Quran meliputi gaya bahasa dan kandungan dalam karya. Juga, sastera Islami adalah sastera yang memberi penekanan kepada mesej atau perutusan bukan kepada bentuk luaran semata-mata. Secara umumnya, penulis merungkai perkaitan mengenai hubungan pengaruh Arab terhadap Melayu dengan mendakwa bahawa wujud golongan sasterawan Melayu yang terpengaruh dengan pemikiran tokoh ilmuwan dari Arab seperti Shafie Abu Bakar, Mohd Kamal Hassan, Shahnon Ahmad dan Ismail Ibrahim. Kajian Adli Yaacob (2006) ini juga banyak membantu pengkaji dalam memahami tasawur awal mengenai intipati sastera Islami melibatkan kebudayaan Arab dan Melayu. 
Antara kajian kesusasteraan bandingan lain yang mengetengahkan mesej Islam sebagai prioriti utama dalam kajian adalah menerusi kajian Pabiyah Hajimaming (2007) yang bertajuk Novel-novel Islami Najib Kailani dan Shahnon Ahmad antara Teori dan Praktis: Kajian Kritikan Perbandingan. Dalam kajian ini, penulis hanya memilih 25 buah novel Najib Kailani dan sembilan buah novel karangan Shahnon Ahmad sebagai sampel kajian utama. Walaupun bilangan sebenar novel yang dihasilkan oleh kedua-dua orang sasterawan ini jauh lebih banyak, namun penulis hanya memberikan perhatian terhadap novel-novel yang dihasilkan oleh keduadua orang tokoh ini selepas mereka aktif dan menghasilkan teori kesusasteraan Islami masingmasing. Ini bagi mengelak berlakunya ketidak adilan dalam menilai karya mereka dan berlakunya bias kerana karya sebelum itu berkemungkinan besar tidak cenderung kepada gaya sastera Islami. Bagi menganalisis novel-novel tersebut, penulis telah menggunakan pendekatan analisis kritikan dengan menitik beratkan empat unsur penting dalam pengkaryaan iaitu plot, gaya bahasa, perwatakan dan latar belakang masa serta tempat. Dengan membandingkan pemikiran kedua-dua orang tokoh berdasarkan novel-novel yang dikaji, penulis mendapati wujud persamaan antara kedua-dua terutamanya kefahaman mengenai Islam yang menjadi teras kepada mereka dalam berkarya dan wujud perbezaan dalam kaedah menginterpretasikan idea dan kekreatifan mereka dalam bentuk karya. Hal ini mungkin disebabkan oleh perbezaan latar belakang mereka yang sedikit berbeza yang secara tidak langsung mempengaruhi cara mereka berkarya. Walaupun demikian, kajian ini mendapati novel-novel yang dihasilkan oleh Najib Kilani lebih menampakkan ‘keIslaman' berbanding novel yang dihasilkan oleh Shahnon Ahmad tetapi masih tidak menafikan kedudukan Shahnon sebagai pencetus kepada kebangkitan sastera Islami di bumi Malaysia.

Kajian Kathirasan (2004) juga mengaplikasikan metode secara perbandingan dalam kajian beliau tetapi lebih memfokuskan kepada kajian pemikiran antara Shahnon Ahmad dan Naguib Mahfouz dalam novel-novel terpilih. Fokus kajian beliau lebih menumpukan pemikiran kedua-dua sasterawan ini yang sangat dikenali dalam lingkungan negara masing-masing sebagai karakter yang memperjuangkan kemaslahatan rakyat melalui medan kesusasteraan. Justeru tidak hairanlah penulis telah memilih dan menganalisis sebanyak sepuluh buah novel iaitu lima buah novel karya Shahnon Ahmad dan lima buah novel karya Naguib Mahfouz yang banyak mengandungi intipati permasalahan sosial dalam lingkungan budaya masing-masing. Pendekatan yang digunakan penulis dalam menganalisis pemikiran kedua-dua orang sasterawan ini adalah berdasarkan pendekatan tematik ataupun tema yang mencirikan empat tema utama yang mendominasikan pemikiran mereka iaitu golongan tertindas, konflik diri, maruah diri dan pegangan agama. Hasil analisis perbandingan oleh penulis mendapati bahawa pemikiran Shahnon Ahmad dalam tema-tema yang dikaji menunjukkan persamaan yang ketara dengan pemikiran Naguib Mahfouz dan ini sekaligus menunjukkan karya tempatan juga menunjukkan mutu yang setanding dengan karya luar yang mendapat pengiktirafan antarabangsa. Tambahan pula, tiada lagi dapatan yang ditemui menyatakan kedua-dua sasterawan ini saling mempengaruhi antara satu sama lain dan dapatan ini menunjukkan citra sebenar kedua-dua sasterawan ini yang banyak merungkaikan permasalahan masyarakat setempat dalam karya-karya berpengaruh mereka.

Selain itu, kajian Ahmad Redzaudin (2005) juga menampilkan kajian perbandingan antara dua orang tokoh berlainan kebudayaan iaitu Shahnon Ahmad dan Najib Mahfuz. Jika dilihat sepintas lalu, kajian beliau dan kajian yang dilakukan oleh Kathirasan (2004) tidak jauh bezanya kerana kedua-dua pengkaji menjadikan Shahnon dan Najib sebagai sampel kajian dan dari segi medan kajian juga hampir sama. Namun kajian beliau yang bertajuk Permasalahan Sosial Dalam Novel-Novel Terpilih Najib Mahfuz dan Shahnon Ahmad: Satu Kajian Perbandingan telah menganalisis 20 buah novel yang terdiri daripada 10 buah novel karya Najib Mahfuz dan 10 buah novel karya Shahnon Ahmad berbanding kajian Kathirasan (2004) yang hanya 
menganalisis 10 buah novel sahaja. Tambahan pula, penulis telah menggunakan pendekatan sosiologikal atau sosiologi sastera untuk melihat sejauh mana kedua-dua pengkarya itu menerima kesan atau refleksi daripada tindak-tanduk masyarakat ketika itu dan menterjemahkan ke dalam karya masing-masing. Rentetan dengan mengetengahkan empat isu utama iaitu kemiskinan, politik, agama dan wanita, penulis mendapati permasalahan yang timbul dalam empat isu utama tersebut adalah benar-benar terjadi namun telah diadaptasi oleh pengkarya mengikut kesesuaian-kesesuaian tertentu. Namun demikian, empat isu yang diutarakan dalam kajian ini merupakan intipati terpenting permasalahan masyarakat ketika itu dan merupakan refleksi sosial sewaktu karya tersebut dihasilkan.

Seterusnya, kajian Mohd Zulkifli (2010) juga mengutarakan kajian perbandingan dua orang tokoh kesusasteraan daripada dua negara yang berbeza iaitu Najib Mahfuz dan A. Samad Said. Namun kajian beliau ini menampilkan sisi yang sedikit berbeza dengan mengutarakan tajuk kajian yang lebih terperinci iaitu Penderitaan Manusia dalan novel-novel terpilih Najib Mahfuz dan A. Samad Said: Satu Kajian Perbandingan. Penulis menganalisis sebanyak tiga buah novel karya Najib Mahfuz iaitu al-Qahirah al-Jadidah, Zuqaq al-Midaq dan Bidayah wa Nihayah manakala tiga buah novel bagi karya A. Samad Said iaitu Salina, Sungai Mengalir Lesu dan Di Hadapan Pulau. Dengan menggunakan metode induktif, analisis deskriptif dan perbandingan, penulis telah mengenal pasti sisi penderitaan yang mendominasi watak-watak yang berkaitan dalam keenam-enam buah novel tersebut dan membuat perbandingan bagi mengenal pasti punca penderitaan yang membelenggu watak-watak terbabit. Hasil kajian mendapati penderitaan yang dialami oleh watak-watak dalam karya A. Samad Said lebih bersifat fizikal seperti kemiskinan, kefakiran manakala penderitaan watak-watak dalam karya Najib Mahfuz lebih bersifat spiritual seperti pegangan agama yang batil dan falsafah kehidupan yang menyeleweng. Kedua-dua jenis penderitaan ini berpunca daripada kelalaian dan kurang penghayatan dalam memahami ajaran Islam yang sebenar. Refleksi daripada kajian perbandingan ini juga menunjukkan tiada kesan dominasi pengaruh Najib Mahfuz ke atas A. Samad khususnya melibatkan aspek kandungan dan nilai estetika disebabkan perbezaan jarak masa antara kedua-dua sasterawan ini sekitar 16 hingga 33 tahun lamanya.

Perbahasan sorotan literatur terakhir yang berkaitan dengan kajian kesusasteraan bandingan adalah kajian Md. Nor (2014) yang memfokuskan kepada kajian perbandingan mengenai kritikan sastera tokoh. Tajuk kajian beliau iaitu Analisis Bandingan Pemikiran Kritikan pemikiran Sastera al-Qadi al-Jurjani dalam al-Wasatah dan 'Abd al-Qahir al-Jurjani Dalam Dala'il al-Ijaz telah dikemukakan untuk memperolehi ijazah Doktor Falsafah pada tahun 2014. Berdasarkan kepada metodologi kajian, penulis menggabungkan empat pendekatan yang berbeza dalam penganalisisan data iaitu pendekatan sejarah, analisis artistik, komparatif dan psikologi dalam merungkai aspek persamaan dan perbezaan dalam kedua-dua karya agung milik dua orang tokoh kesusasteraan ini. Hasil kajian mendapati kedua-dua orang tokoh ini berkongsi pandangan dalam beberapa aspek pemikiran kritikan sastera seperti pemisahan alisti arah daripada al-tashbih al-baligh dan berbeza pandangan dalam beberapa sudut yang lain seperti isu sastera dan agama, plagiarism dan teori bahasa sastera. Kajian perbandingan ini secara keseluruhannya telah membuktikan bahawa perbezaan pandangan dalam pemikiran kritikan sastera tidak menghalang mereka dalam menyumbang intipati kelimuan dalam bidang kritikan sastera agar kelihatan lebih mapan dan paling utama saling melengkapi kekurangan yang ada antara satu sama lain.

Perbahasan seterusnya adalah mengenai kajian pemikiran tokoh yang juga merupakan penutup bagi perbahasan sorotan literatur pada sub topik yang kedua ini. Pemikiran tokoh yang dikaji adalah merujuk kepada tokoh yang menjadi sampel pada tajuk kajian sorotan literatur ini iaitu Sayyid Sayyid `Abd al-Raziq dan Mohd Affandi Hassan. Sepanjang pengamatan penulis setakat ini, terdapat dua kajian ilmiah yang ditemui membahaskan mengenai pemikiran atau 
aspek yang berkaitan dengan Sayyid Sayyid `Abd al-Raziq manakala bagi Mohd Affandi Hassan terdapat tiga kajian yang mengkaji mengenai pemikiran beliau secara khusus. Ini dapat diltelusuri melalui kajian Zulkarnain (2011a; 2011b) yang membahaskan pendekatan ta'amul. Dalam kedua-dua kajian tersebut, beliau telah menampilkan sisi pendekatan yang sedikit berbeza dengan menggabungkan dua teori yang berasingan kepada satu bentuk pendekatan teori yang lebih kuat dan mapan iaitu pendekatan ta'amul-taklif. Pendekatan ta'amul pada asalnya adalah idea yang diutarakan oleh Abd Al-Raziq (2002) namun telah dilanjutkan perbahasan kepada elemen dilalah dan semiotik. Secara umumnya, dilalah dan semiotik membawa pengertian sebagai permaknaan namun nilai permaknaan dilalah adalah bersifat tetap bertunjangkan akidah, syariat dan akhlak manakala nilai permaknaan semiotik bersifat melewati batasan dan bebas.

Menyentuh mengenai kajian pemikiran Mohd Affandi Hassan pula, dapat disoroti melalui kajian Wan Zaida (2010) yang bertajuk Pemikiran Dalam Novel Mohd Affandi Hassan: Analisis Dari Sudut Kajian Budaya yang merupakan disertasi sarjana setebal 368 halaman. Penulis telah memilih lima buah novel karangan Mohd Affandi Hassan iaitu Tampang Sasterawan, Citra Pujangga, Wajah Pendeta, Aligupit dan Jejak Warisan dengan menggunakan pendekatan konsep kajian budaya dalam sastera janaan Chris Barker dan Nyoman Kutha bagi menggeledah sudut-sudut budaya dalam lima buah novel tersebut. Justeru, penganalisisan kritis penulis terhadap tiga aspek yang dipilih sebagai tema kajian iaitu identiti budaya, gender dan pembinaan bangsa serta hegemoni politik telah menatijahkan pemikiran Mohd Affandi Hassan yang mendepani nilai teras dalam budaya iaitu agama yang murni sebagai pencerahan entiti mahupun etnik bagi melawan liberalisme dan sekularisme yang bertopengkan modenisme.

Kajian R. Sharatha (2007) juga tidak ketinggalan dalam membahaskan mengenai pemikiran Mohd Affandi Hassan melalui kajiannya yang memberi fokus kepada novel Pujangga Melayu sebagai korpus utama kajian. Kajian beliau yang bertajuk Pujangga Melayu: Dari Sudut Pendekatan Persuratan Baru telah menganalisis empat buah novel rangkaian yang terdapat dalam Pujangga Melayu iaitu Jejak Warisan (1994), Citra Pujangga (1994), Tampang Sasterawan (1994) dan Wajah Pendeta (1996). Sebenarnya, empat buah novel rangkaian ini saling bersambung sifatnya dan mempunyai aliran cerita yang saling berkaitan lalu dikumpulkan membentuk satu novel penuh oleh pengkarya Mohd Affandi Hassan. Umumnya, pendekatan persuratan baru yang menitikberatkan dua aspek iaitu pemikiran dan stylization of idea (siratan makna) telah dijadikan alat analisis dalam menilai karya-karya tersebut. Justeru, hasil dapatan kajian menunjukkan pemikiran pengkarya iaitu Mohd Affandi Hassan lebih mengutamakan nilai keilmuan berbanding semata-mata cerita dalam membangunkan novel Pujangga Melayu dan ini merupakan manifestasi daripada pengalaman rohaniah beliau yang begitu komited terhadap Islam sebagai pegangan hidup yang kekal dan pasti.

Buat akhirnya, kajian Mohd Zariat (2004) juga ada membahaskan pemikiran Mohd Affandi Hassan namun bukan dalam skala yang besar. Ini kerana kajian beliau yang bertajuk Seksualiti Dalam Novel Melayu: Satu Analisis Teks Berdasarkan Persuratan Baru lebih menumpukan kepada penganalisisan 20 buah novel Melayu antaranya seperti Salina, Tivi, Desa Pingitan, Shit, Sami Mekong, Iakah Salmah, Terdedah, Kuala Lumpur Kita Punya, dan lain-lain yang menjadi batasan dalam kajian ini. Namun beliau menggunakan pendekatan Persuratan Baru janaan Mohd Affandi Hassan sebagai kerangka analisis utama dalam menilai karya-karya tersebut berdasarkan dua ciri utama yang mendasari Persuratan Baru iaitu isi (content) dan bentuk (form). Analisis kajian juga mendapati novel-novel tersebut lebih mengutamakan 'cerita' berbanding 'ilmu' disamping wujud manifestasi-manifestasi seks yang dijadikan alat untuk memperhebatkan keseluruhan cerita. Walaupun demikian, ini ternyata berbeza dengan persoalan seksualiti dalam novel Pujangga Melayu yang juga turut dikaji oleh penulis dalam kajian ini sekitar 40 halaman. Ini kerana pemahaman seksualiti yang terkandung dalam novel 
Vol. 8: (Dec.) 2015

itu sejajar dengan falsafah dan pendekatan Persuratan Baru yang bertunjangkan taklif, iaitu perakuan terhadap keterikatan manusia kepada sang Pencipta.

\section{Analisis Sorotan Literatur}

Pada bahagian ini, analisis akan dibahagikan kepada dua bahagian iaitu gagasan dan kritikan terhadap sastera Islami serta contoh kajian kesusasteraan bandingan dan pemikiran tokoh. Sorotan literatur ini akan dianalisis menerusi hasil kajian bagi literatur-literatur yang telah dipilih bagi melihat justifikasi kepada perlunya kajian ini dilakukan.

\section{Gagasan dan Kritikan Terhadap Sastera Islami}

Berdasarkan sorotan literatur yang telah dilakukan, kekaburan mengenai falsafah dan pemahaman sastera Islami seringkali menjadi permasalahan dan polemik di kalangan cendekiawan mahupun pengkaji yang terlibat secara khusus dalam lapangan kesusasteraan ini. Ini menyebabkan mereka lebih banyak terlibat dalam perdebatan dan ketidak sepakatan yang akhirnya tidak membawa apa-apa keuntungan kepada lapangan ini. Tambahan pula, wujud ramai golongan pengkarya mahupun penulis yang menyatakan bahawa mereka merupakan penulis bergenre Islami namun setelah meneliti hasil karya mereka wujud satu percanggahan yang berbeza dengan apa yang didakwa sebelum itu. Fenomena ini wujud berikutan ketidak jelasan mengenai peranan mereka dan persoalan mengapa dijadikan di muka bumi ini sebagai seorang khalifah. Kegagalan memahami peranan sebagai khalifah telah membawa kepada satu manifestasi yang buruk dan telah membawa kemudaratan dan kerosakan khususnya dalam lapangan kesusasteraan Islami. Akibatnya, telah wujud pelbagai karya yang menghina dan mencemarkan kesucian Islam melalui hasil karya golongan yang menganuti Islam tetapi hakikatnya mereka tidak ubah seperti golongan yang bertopengkan Islam dan menggunakan nama agama untuk mencapai populariti keduniaan yang diidamkan. Juga disebabkan oleh kegagalan memahami pemaknaan sastera Islami yang meliputi aspek peranan dan fungsi sepertimana yang diutarakan oleh kajian al-Rahawi (2009).

Kegagalan memahami fungsi sastera Islami juga merupakan antara faktor penting yang membawa kepada pengabaian ketanggung jawaban dan etika ketika berkarya namun lebih daripada itu adalah disebabkan oleh ketiadaan satu metodologi atau manhaj yang khas dan menyeluruh dalam memandu mereka bagi menghasilkan sesebuah karya yang berteraskan Islam. Ini terbukti dengan kajian cImad Al-Din Khalil $(1998,2009)$ yang menggesa supaya membina satu metodologi khas untuk panduan para pengkarya dalam memanfaatkan fundamental Islami dalam karya mereka bagi mengelakkan berlakunya penyelewengan dan penghinaan terhadap Islam. Kajian Bin Isa (1998) juga menyuarakan nada yang sama dalam kajian beliau apabila pencetus gerakan sastera Islami, Syeikh Abu Hasan Al-Nadwi mengharapkan satu perubahan besar dalam membina semula pemahaman sastera Islami yang sempurna bagi mengekang penyelewengan-penyelewengan yang telah lama berlaku.

Meskipun telah wujud idea dan teori berkaitan sastera Islami seperti iltizam, ta ‘amul dan taklif seperti kajian 'Abd Al-Raziq (2002, 2009), Mohd Affandi Hassan (2005), Mujahid Mustafa Bahjat (2009), Zulkarnain Mohamed (2011) dan Mohd Shahrizal \& Mohd Firdaus (2013), namun idea dan teori tersebut hanya berlegar dan membahaskan secara teoritikal yang bersifat asas. Tanpa menidakkan kehebatan kajian-kajian tersebut yang telah membina tapak kukuh dalam memperkembangkan lagi idea dan prinsip sastera Islami, sesuatu yang difikirkan perlu bagi menyediakan kajian lanjutan yang bersifat perbandingan dengan kebudayaan lain yang juga memiliki aspirasi yang sama berkaitan lapangan ini. Kajian Zulkarnain Mohamed $(2009,2010)$ juga memperincikan panduan menganalisis Al-Quran dan Hadith dalam karya 
sastera dalam skop yang kecil dan terhad namun masih perlu dijadikan sandaran sumber bagi lanjutan kajian yang dicadangkan dalam literatur ini. Secara keseluruhan, gesaan untuk menyediakan satu metodologi menyeluruh dan komprehensif terhadap pemahaman semula gagasan sastera Islami bukanlah satu cakap biasa ataupun bersifat santai. Ia hadir dangan nada berlainan dalam kebanyakan makalah dalam sorotan literatur ini yang melambangkan keseriusan dan keperluan bagi merangka kembali kefahaman yang mampu membawa khalayak khususnya lebih yakin dan tidak meragui akan kemampuan Islam dalam pembinaan metodologi kritikan sastera tersendiri.

\section{Contoh Kajian Kesusasteraan Bandingan dan Pemikiran Tokoh}

Melalui analisis terhadap sorotan literatur terhadap bahagian kedua ini, terdapat dua pembahagian skop analisis yang akan diberi tumpuan. Pertama berkaitan dengan kajian kesusasteraan bandingan, terdapat tiga kajian perbandingan yang hampir menyamai dengan tajuk sorotan literatur ini iaitu kajian Rahmah Ahmad \& Mohd Shahrizal (2011), kajian Mohd Faizal (2010) dan kajian Adli Yaacob (2006). Kajian Rahmah Ahmad \& Mohd Shahrizal (2011) menumpukan terhadap perbandingan pemahaman sastera Islami antara dua orang tokoh berlainan kebudayaan iaitu Mohd Affandi Hassan dan Abu Hasan Ali An-Nadwi manakala kajian Mohd Faizal (2010) membandingkan fenomena, wacana dan penerapan sastera Islami di Malaysia dan Indonesia. Kajian Adli Yaacob (2006) pula membuat perbandingan pemahaman sastera Islami pada era moden antara sasterawan Arab dan sasterawan Melayu. Secara realitinya, kajian-kajian perbandingan yang disebutkan di atas telah menampakkan satu ruang kompromi antara satu sama lain dalam menilai dan mentafsirkan sastera Islami itu berdasarkan ilmu dan kefahaman masing-masing namun tidak membatasi sempadan syariat yang ditetapkan. Meskipun tidak dinafikan wujud perbezaan dalam memberikan maksud dan kefahaman, akan tetapi ia hanya tertumpu kepada persoalan cabang yang lebih bersifat relatif dan bukannya menganggu persoalan pokok dalam sastera Islami. Ketiga-tiga kajian bersetuju untuk meletakkan dasar akidah dan pengharmonian terhadap elemen syariat dan akhlak sebagai teras penting dalam penjanaan sastera Islami supaya ia lebih stabil dan tidak mudah dimanipulasikan tafsiran ini oleh ideologi-ideologi lain yang menyeleweng.

Selain itu juga, kajian kesusasteraan bandingan lain yang menyentuh isu selain daripada gagasan sastera Islami juga telah menonjolkan bahawa kajian seumpama ini wajar dilakukan pada masa mendatang. Walaupun kajian Pabiyah (2007), kajian Kathirasan (2004), kajian Ahmad Redzaudin (2005) dan kajian Mohd Zulkifli (2010) mengetengahkan isu kajian yang berlainan daripada sastera Islami, namun perbandingan yang diterapkan dengan memilih dua orang tokoh berlainan kebudayaan dan dalam konteks kajian mereka berempat adalah budaya Arab dan Melayu telah menampilkan sisi keistimewaan tersendiri. Sisi keistimewaan tersebut ialah kewujudan persamaan dalam aspek-aspek tertentu meskipun bukan berasal daripada kebudayaan yang sama. Ini kerana kewujudan faktor atau ciri "genetik" yang sama telah memungkinkan wujud persamaan antara kedua-dua tokoh yang dikaji. Ini menyerlahkan keistimewaan kajian secara perbandingan yang mampu menonjolkan kesatuan pemikiran secara tidak langsung walaupun kemungkinan kedua-dua tokoh yang dikaji tidak pernah mengenali antara satu sama lain ataupun mungkin tidak pernah hidup sezaman. Kajian Md Nor (2014) juga menyerlahkan metodologi perbandingan ini sebagai satu metode yang perlu diberi keutamaan oleh pengkaji apabila wujud persamaan pemikiran kritikan sastera antara al-Qadi al-Jurjani dan `Abd al-Qahir al-Jurjani meskipun banyak pendapat yang menyatakan mereka tidak hidup sezaman dan tidak pernah berjumpa. 
Kedua, berkaitan dengan kajian pemikiran tokoh iaitu Mohd Affandi Hassan dan Sayyid Sayyid `Abd al-Raziq, tiga kajian berkaitan dengan Mohd Affandi Hassan yang ditemui suduh cukup untuk menggambarkan sesuatu yang unik pada pemikiran dan susuk tubuh beliau. Pernah berkhidmat dalam perkhidmatan awam sebagai Pegawai Tadbir dan Diplomatik (PTD) sebelum menceburi secara aktif dalam lapangan kesusasteraan selepas bersara sepenuhnya, beliau dilihat merupakan ikon penting dalam pembinaan gagasan sastera Islami di Malaysia khususnya selepas era polemik sekitar tahun 80-an. Ini dibuktikan dengan pembawakan idealisme utama beliau melalui Persuratan Baru yang mengangkat ilmu sebagai wadah kesusasteraan berdasarkan kajian Wan Zaida (2010), kajian R. Sharatha (2007) dan kajian Mohd Zariat (2004). Ketiga-tiga kajian tersebut telah menatijahkan pemikiran Mohd Affandi Hassan yang bertunjangkan kepada ilmu dan akidah yang benar melalui novel beliau yang terkenal iaitu Pujangga Melayu sekaligus mengangkat martabat beliau sebagai tokoh kesusasteraan Islami yang disegani di bumi Malaysia. Bertitik tolak daripada itu, pengkaji berpendapat bahawa pemikiran gagasan sastera Islami Mohd Affandi Hassan sangat wajar dilakukan namun memberi penekanan kepada aspek perbandingan terhadap seorang lagi tokoh dari dunia Arab iaitu Sayyid Sayyid `Abd al-Raziq. Walaupun beliau bukanlah nama besar tokoh sastera Islami Arab yang lain seperti Muhammad Qutb, Najib Kilani mahupun yang lain-lain, namun sumbangan beliau dalam menghasilkan sebuah buku yang bertajuk Manhaj al-Islam fi alNaqd al-Adabi adalah sesuatu yang sangat berharga khususnya dalam dunia kesusasteraan Islami sejagat. Sewajarnya, perbandingan antara kedua-dua orang tokoh berlainan kebudayaan ini sangat menarik untuk dilaksanakan dan diperhalusi agar dapat memberi sumbangan khazanah ilmu yang bermanfaat.

Justeru, berdasarkan analisis kedua-dua bahagian dalam sorotan literatur ini, terdapat dua rumusan penting yang boleh dilakukan. Pertama, sepanjang pemerhatian yang dilakukan pengkaji, tiada lagi kajian yang menyentuh secara perbandingan antara Sayyid Sayyid 'Abd alRaziq dan Mohd Affandi Hassan mengenai gagasan sastera Islami secara khusus dan mendalam. Perbandingan gagasan sastera Islami antara kedua-dua orang tokoh berlainan kebudayaan ini adalah sesuatu yang menarik untuk dikaji memandangkan kelebihan mereka berdua dalam mengemukakan idea masing-masing yang bersifat kontemporari malahan menjadi contoh kepada penggiat lain. Kedua, daripada aspek metodologi yang mengaplikasikan kaedah perbandingan, fokus akan diberikan dengan melihat kepada falsafah, pandangan dan disiplin terapan oleh kedua-dua orang tokoh ini bagi melihat keupayaan mereka dalam menjana pemikiran masing-masing yang subjektif sifatnya. Pastinya wujud persamaan dan perbezaan antara kedua-duanya namun kajian ini dilihat perlu dilakukan bagi mengimbangi kefahaman khalayak terhadap sastera Islami dan perlu dimurnikan semula dengan kaedah perbandingan melalui pandangan dan idea daripada dua tokoh iaitu Mohd Affandi Hassan dan Sayyid Sayyid Abd al-Raziq. Ini kerana sumbangan mereka khususnya dalam falsafah kesusasteraan Islami adalah sesuatu yang amat besar jasanya dan banyak manfaatnya dalam mengembalikan kefahaman yang asli dan sebenar kepada para penggiat kesusasteraan dan khalayak. 


\section{References}

Al-Quran.

`Abd al-Raziq, Sayyid Sayyid. 2002. Al-Manhaj al-Islami fi al-Naqd al-Adabi. Beirut: Dar al-Fikr alMu`asir.

`Abd al-Raziq, Sayyid Sayyid. 2009. Mustalah al-Iltizam fi al-Naqd al-Islami al-Mu’asir: Dirasah fi al-Mafhum wa Majalat al-Istikhdam. Islamiah al-Ma rifah 58: 45-78.

Adli Yaacob. 2006. Mafhum al-Adab al-Islami' fi al-'Asr al-Hadith bayn al-Udaba' al-Arab wa alMalayuyin: Dirasah Muqaranah. Tesis Doktor Falsafah, Universiti Islam Antarabangsa Malaysia.

Ahmad Redzaudin Ghazali. 2005. Permasalahan sosial dalam novel-novel terpilih Najib Mahfuz dan Shahnon Ahmad: satu kajian perbandingan. Disertasi Sarjana, Universiti Kebangsaan Malaysia.

Bin Isa Batahir. 1998. Al-Adab al-Islami wa Naqdihi Ind al-Syeikh Abi al-Hasan al-Nadwi. Islamiah al-Ma'rifah 12: 99-131.

'Imad al-Din Khalil. 1998. Haul Harakah al-Adab al-Islami al-Mu`asir: Waqfah li Muraja`ah alHisab. Islamiah al-Ma'rifah 12: 11-37.

'Imad Al-Din Khalil. 2009. Haul al-Madhmun al-Fikri Liladab al-Islami al-Mu`asir: Islamiah alMairifah 58: 5-22.

Kathirasan a/l Doraisamy. 2004. Pemikiran Shahnon Ahmad dan Naguib Mahfouz dalam novelnovel terpilih : satu perbandingan. Tesis Doktor Falsafah, Universiti Malaya.

Md. Nor Abdullah. 2014. Analisis bandingan pemikiran kritikan sastera al-Qadi al-Jurjani dalam al-Wasatah dan Abd al-Qahir al-Jurjani dalam Dalaìl al-Ijaz. Tesis Doktor Falsafah, Universiti Kebangsaan Malaysia.

Mohd Affandi Hassan. 2005. Pendidikan Estetika daripada Pendekatan Tauhid. Ulang Cetak. Kuala Lumpur: Dewan Bahasa dan Pustaka.

Mohd. Faizal Musa. 2010. Sastera Islam: fenomena, wacana dan penerapannya di Malaysia dan Indonesia. Tesis Doktor Falsafah, Universiti Kebangsaan Malaysia.

Mohd Shahrizal Nasir \& Mohd Firdaus Yahaya. 2013. Peranan novelis Muslim dalamusaha menyebar al-ma'ruf dan menyekat al-mungkar. Jurnal ILIM 6: 209-230.

Mohd Zariat Abdul Rani. 2004. Seksualiti dalam novel Melayu: satu analisis teks berdasarkan persuratan baru. Tesis Doktor Falsafah, Universiti Kebangsaan Malaysia.

Mohd Zulkifli Ismail. 2010. Al-Shiqa' al-Insani fi Riwayat Mukhtarah li Najib Mahfuz wa Abd Samad Said dirasah muqaranah. Tesis Doktor Falsafah, Universiti Islam Antarabangsa Malaysia.

Mujahid Mustafa Bahjat. 2009. Al-Jamal wa al-Iltizam fi al-Fan al-Islami. Islamiah al-Ma'rifah 56: 85-114.

Pabiyah Hajimaming. 2007. Riwayah Najib Kilani wa Shahnon Ahmad al-Islamiyah bayn alNazariyah wa al-Tatbiq dirasah naqdiah muqaranah. Tesis Doktor Falsafah, Universiti Islam Antarabangsa Malaysia.

al-Rahawi, Faris `Abdallah Badr. 2009. Al-Adab al-Islami wa Fa`iliah Sultoh al-Markaz Bayn Dilalati al-Tausif wa al-Tauzif. Islamiah Al-Ma 'rifah 58:79-103.

Rahmah Ahmad H. Osman \& Mohd Shahrizal Nasir. 2011. Sastera Islam: satu perbandingan antara pandangan Mohd Affandi Hassan dan Abu al-Hasan Ali al-Nadwi. Jurnal Elektronik Jabatan Bahasa dan Kebudayaan Melayu 3: 1-40.

R. Sharatha a/p Ramasamy. 2007. Pujangga Melayu: dari sudut pendekatan persuratan baru. Disertasi Sarjana, Universiti Malaya.

Wan Zaida Wan Yussof. 2010. Pemikiran dalam novel Mohd Affandi Hassan: analisis dari sudut kajian budaya. Disertasi Sarjana, Universiti Malaya. 
Zulkarnain Mohamed. 2009. Etika Menganalisis Al-Quran dan Hadith Dari Sudut Sastera. Dlm. Muhammad Bukhari Lubis, Mohamed Pitchay Gani \& Mohamed Abdul Aziz (pnyt). Sumbangsih Tizkari Buat Masuri S.N, hlm. 228-258. Tanjung Malim: Penerbit Universiti Pendidikan Sultan Idris.

Zulkarnain Mohamed. 2010. Al-Qur'an, Ilmu, Displin Islami dan Sastera. Dlm. Ungku Maimunah Mohd Tahir (pnyt). Kedudukan Ilmu dalam Kesusasteraan Teori \& Praktis, hlm. 83-157. Bangi: Institut Alam dan Tamadun Melayu, Universiti Kebangsaan Malaysia.

Zulkarnain Mohamed. 2011a. Pendekatan ta'amul-taklif dalam kajian sastera. International Journal of the Malay World and Civilisation 29(2):137-152.

Zulkarnain Mohamed. 2011b. Batasan berkarya menurut akidah Islamiah: kajian Awlad Haratina oleh Najib Mahfuz, Diwan oleh 'Abd Al-Wahhab Al-Bayati dan "Langit Makin Mendung" oleh Kipandjikusmin. Tesis Doktor Falsafah, Universiti Pendidikan Sultan Idris. 